\title{
Recent Developments in Nanomaterials Based Adsorbents for Water Purification Techniques
}

\author{
Maheshwara Reddy Jedla ${ }^{1}$, Bhargavi Koneru ${ }^{2}$, Adolfo Franco Jr ${ }^{3 \mathbb{D}}$, Dinesh Rangappa ${ }^{4}$, , Prasun \\ Banerjee 2,*(D)
}

1 Department of Mechanical Engineering, Gandhi Institute of Technology and Management [GITAM] University, Bengaluru, Karnataka, India; jmahesh1999@gmail.com (M.R.J.);

2 Multiferroic and Magnetic Material Research Laboratory (MMMRL), Gandhi Institute of Technology and Management (GITAM) University, Bengaluru, Karnataka, India.; bkoneru @ gitam.in (B.K.); pbanerje @ gitam.edu (P.B.);

3 Instituto de Física, Universidade Federal de Goiás, Goiânia, Brazil; franco@ufg.br (A.F.J.);

4 Department of Applied Sciences, Visvesvaraya Technological University, Bengaluru, Karnataka, India; dineshrangappa@gmail.com (D.R.);

* Correspondence: pbanerje@ gitam.edu (P.B.);

Scopus Author ID 57197478910

Received: 19.08.2021; Revised: 28.09.2021; Accepted: 2.10.2021; Published: 24.10.2021

\begin{abstract}
Currently, most advanced technologies employ nanomaterials due to the modern tailor-made properties these materials exhibit compared to their bulk counterparts. Nanomaterials have attracted researchers around the globe in the last few decades due to their unusual properties due to the presence of a greater number of carriers at the surface, which affects the chemical and physical properties of these materials. Ensuring pure drinking water for domestic purposes is the biggest challenge in current times. Industrialization is increasing with time due to human needs. The extensive use of fertilizers to enhance agricultural productivity has hazardous effects on the ecosystem. Water pollution will significantly impact living beings on the land and aquatic beings, followed by terrestrial, aerial flora, and fauna. In a world full of technologies, there are many methods to purify water (water filters, RO purifiers, etc.). Still, nanotechnology plays a vital part in purifying water on a large scale. Nanotechnology methods came up with new materials and analytical techniques that can treat the byproducts that are toxic to the environment. Heterogeneous photocatalysis used with metal oxide nanostructures causes no harm to the ecosystem. Nanomembranes and Nanostructures will play an active role by acting as a trap for many Nano pollutants. This review presents nano cellulose, nanocarbon tubes, and nanomembranes used in water purification and analytical techniques by addressing the current economic water purification techniques.
\end{abstract}

Keywords: nanoparticles; ion-exchange techniques; water softening; purification and separation of chemicals.

(C) 2021 by the authors. This article is an open-access article distributed under the terms and conditions of the Creative Commons Attribution (CC BY) license (https://creativecommons.org/licenses/by/4.0/).

\section{Introduction}

The nanoparticles with one billionth $\left(10^{-9}\right)$ of meter particle size significantly impact the growth of present-day technologies in the $21^{\text {st }}$ century [1]. The surface characteristics of these materials play a significant role in designing technologies in various fields, which has driven the interest of research teams in nanotechnology.

Most of the nanomaterials can be classified as colloids. The nanoparticles have the attractive property because of the van der Waals forces, making them behave as a colloid. These colloids are formed by steric stabilization by the absorption of the surfactants and polymers. 
The stabilization can be done with coating on the surfaces [2]. It will significantly reduce water pollution with the new nanostructure and materials because of its surface property. It is a multidimensional and complex problem that interested most researchers in developing different materials at various water purification stages shown in Fig. 1. New methods in water purification are essential for the modern world to address current issues.

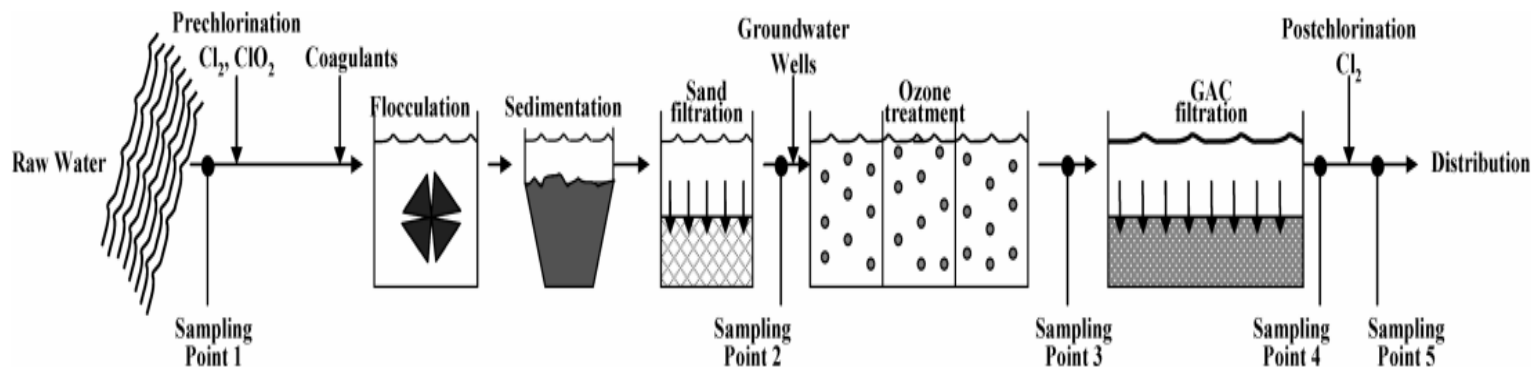

Figure 1. Drinking water treatment scheme for treatment plant [DWTP] [3]. Reprinted (adapted) with permission from ACS Environmental science \& technology; 10.1021/es800768h. Copyright (2008) American Chemical Society.

The primary source of waste generated water pollutants by hospitals, industries, agriculture, and household activities contains non-metabolized and metabolized particles. Polluted water contains these chemicals, medicines, detergents, and additives, which considerably impact human health, especially children and aged people. According to WHO, millions of people have no supply of pure drinking water [4]. The drinking water cost has grown significantly over the past few decades because of climate changes, increasing energy costs, population growth, and environmental factors. Traditional water treatment cannot remove the contaminants from water, which affects water quality [5]. The contamination can be surface or bulk ions, which can penetrate aqua filters.

The challenges bring focus on looking for alternative methods and pollution remediation methods [6]. Keeping this issue in mind, various DWTPs are proposed and operate experimentally at different field levels. The primary techniques are screening, filtering, coagulating, centrifugation, sedimenting, separation, and flocculation. The secondary methods are anaerobic and aerobic techniques. The tertiary methods are crystallization, distillation, extraction of solvents, evaporating, precipitating, oxidation, exchange of ions, nanofiltration, reverse osmosis, ultrafiltration, adsorption, microfiltration, and electrolysis [7]. The demand for cost-effective pure and potable drinking water is gaining worldwide attention using sustainable methods.

The expected population explosion of humankind creates much pressure on the supply of pure drinking water with a present threshold of $1700 \mathrm{~m}^{3} /[$ person-year]. Heavy metals in the water are one of the serious issues these days. A study has been carried out in China, which has the fastest growth in the economy, has only $40 \%$ of the groundwater, which is usable, and $28 \%$ of the improper to be used for industrial purposes [8]. Nanomaterials have gained importance in water purification as they can be used as membranes by forming a solid matrix. These membranes can exhibit improvement in the properties of chemical separation and mechanothermal stability with the proper selection of nanomaterials. This review will discuss the emerging technologies of Nanotechnology-based materials and their analytical applications intended for water purification. 


\subsection{Technologies for water purification.}

The traditional water purification methods [Fig 1.2] are distillation, chemical methods, coagulation and flocculation, biological treatment, treated with UV, RO, ultrafiltration, nanofiltration, microfiltration, and carbon nanofiber methods. However, these traditional technologies will purify the water to the extent that it cannot be potable for drinking purposes. The new technology which has emerged by using the concepts of Nanotechnology can provide a solution to obtain potable water. Nanotechnology is used in absorbing nano metals and nonmetal oxides, effective photocatalysis, membranes for filtering and hindering microbial growth, and disinfection.

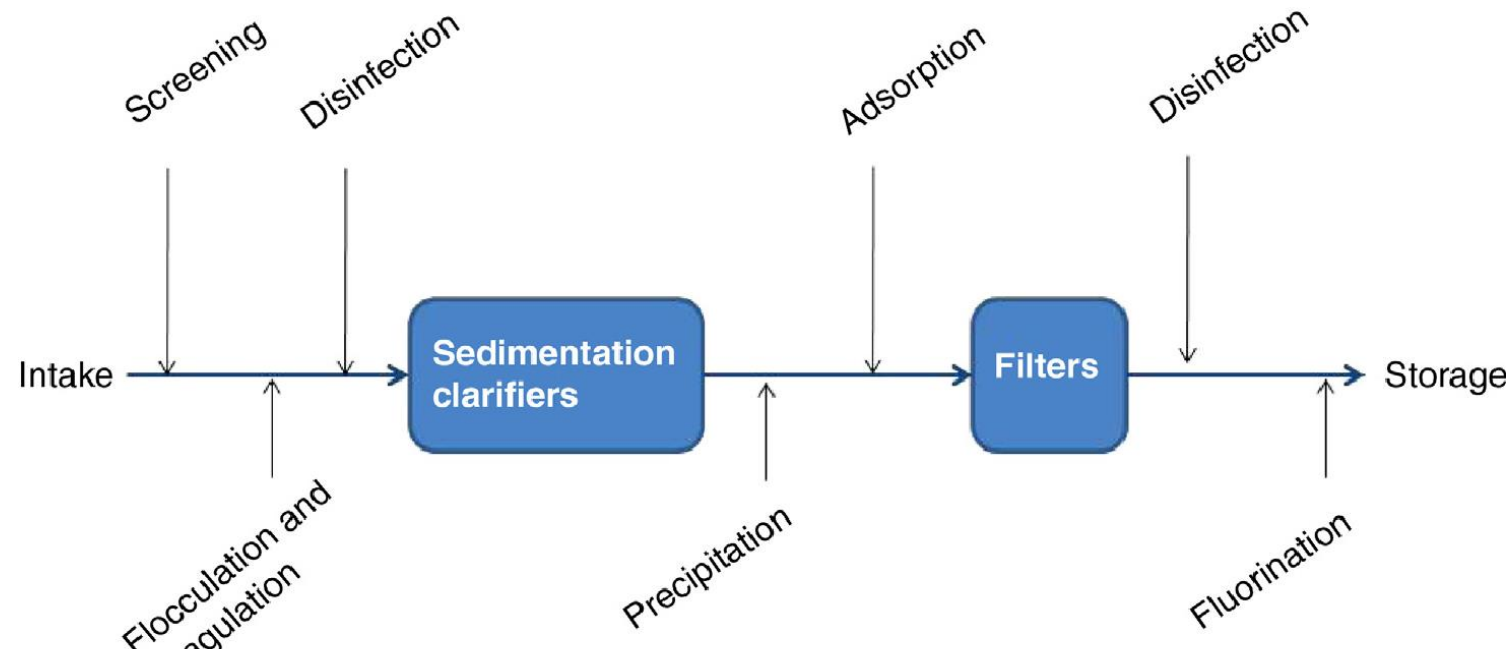

Figure 1.2. Water purification process.

\section{Nanomaterials for Water Purification}

\subsection{Area specific effectiveness}

The nanomaterial's effectiveness for efficiently removing the water's impurity is highlighted in the Table. 1.

Table 1 Available nanomaterial and their effectiveness in the specific area.

\begin{tabular}{l|l} 
Nanomaterial & Effective in removing/ treating \\
\hline $\mathrm{Ag} / \mathrm{TiO}_{2}$ nano filter membrane [9] & Bacteria \\
\hline Alumoxane derived Alumina membrane [10] & dye \\
\hline Alumina membranes derived from polystyrene sulfonate [11] & Cations with divalent nature \\
\hline Amino acid homopolymers derived silica membranes [12] & Metals \\
\hline Polymeric or alumina membranes with Au nanoparticles [13] & 4- Nitrophenol \\
\hline Titanium oxide filters [14] & PAHs \\
\hline $\mathrm{TiO}_{2} / \mathrm{Al}_{2} \mathrm{O}_{3}$ compositive membranes [15] & Direct black 168 dye \\
\hline $\mathrm{TiO}_{2}$ nanophotocatylicnano membrane [16] & Methyl orange, azo dye \\
\hline $\mathrm{Silicon}$ carbon filters [17] & Trihalogenmethanes, PHAs \\
\hline Nanocrystalline zeolites [18] & Tolerance, nitrogen dioxide \\
\hline Synthetic zeolite [19] & Humic acid \\
\hline Graphitized CNT [20] & 1,2 Dichlorobenzene \\
\hline $\mathrm{CeO}{ }_{2}$-CNTs [21] & Metal ions \\
\hline $\mathrm{CNT}[22]$ & p- Nitro-phenol \\
\hline Polyethyleneimine with Carbon NPs [23] & Metals \\
\hline $\mathrm{CNT}$ hydride [24] & arsenate \\
\hline $\mathrm{CNT}$ sheets [25] & Metal ions \\
\hline $\mathrm{CNT} / \mathrm{Fe}[26]$ & Toluene, Benzene, dimethyl \\
\hline MWCNTs and SWCNTs [27] & Roxarsone, Trihalomethanes \\
\hline Mesoporous aluminosilicate spheres with nanosized $\mathrm{Fe}_{3} \mathrm{O}_{4}[28]$ & mercury
\end{tabular}


Nanomaterial

Silica coated $\mathrm{Fe}_{3} \mathrm{O}_{4}[29]$

Humic acid/ $/ \mathrm{Fe}_{4} \mathrm{O}_{3}[30]$

\section{Nanomaterials for water purification}

\subsection{Zeolite-based nanomaterials.}

These naturally occurring materials can also be prepared artificially on a large scale or at a laboratory level. More than 40 zeolites are naturally available, among which clinoptilolite the most accessible. These are three-dimensional structures with a -ve charge produced with $\mathrm{Si}^{4+}$ structure replaced with $\mathrm{Al}^{3+}$ [31-34]. Generally, they contain silicon, aluminum, and oxygen in their formation of structures. The zeolites are synthesized with coal fly ash or siliconaluminum solutions and used for adsorbents in column filters. Some of the zeolites are inexpensively synthesized; among them, $\mathrm{NaP} 1$ is most extensively used, with a chemical formula of Na6Al6Si10O32, 12H2O, and $\mathrm{Na}[\mathrm{I}]$ as ions. This zeolite is mainly for the heavy metals present in the waste of acid mines. Zeolite-coated ceramic membranes have gained importance for their filtration sensitivity to a range of ultra-filtration by having solute particles of the size, which can be filtered by NF or even RO membranes [35-40]. The containment will be a function of ratio, temperature, types of ions, and water. The familiar zeolites are inverted to sodalite [SOD], [MFI] - class, and the Linde type A [LTA]. Fig 2 presents the fabrication process and the structure of ZIF-8 with CNTs [41-45].
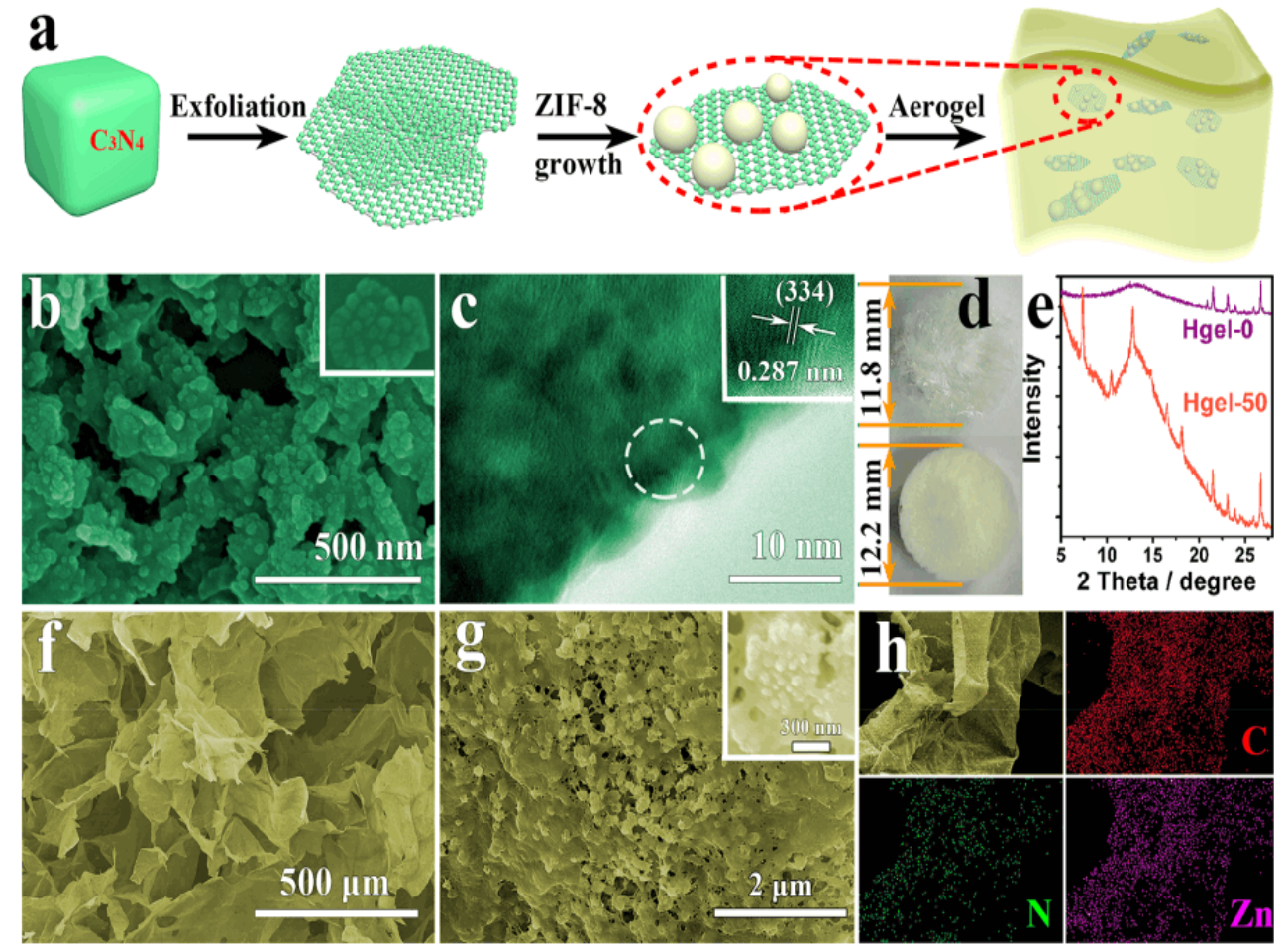

Figure 2 (a) fabrication, (b) SEM, (c) HRTEM, (d) photo (e) XRD (f) different magnified SEM, (g) and (h) EDX of ZIF and CNTs hybrid framework [41]. Reprinted (adapted) with permission from ACS Sustainable Chemistry \& Engineering; 10.1021/acssuschemeng.7b02376. Copyright (2017) American Chemical Society.

\subsection{Inorganic-organic TFN [Thin Film Nano] membranes.}

These membranes are mainly known for their enhanced mechanical, chemical, thermal stability, permeability, and permittivity properties. To make use of the properties exhibited by nanomaterials, the nanoparticles are introduced into a macroscopic material. During the 
processing, nanophases are dispersed across the material. This decreases the mass fraction of the NPs [46].

Recent research is focused on incorporating Nanomaterials into microfiltration as well as ultrafiltration membranes. It improves permeability, decreases porosity to capture the Nanosized particles, fouling, pollutant degradation targeting, and enhances thermal and mechanical stabilities. Increasing water permeability did not have a direct effect on the decrease of TDS [47].

\subsection{Carbon nano tubes (CNT).}

Carbon nanotubes (CNT) are the most popular type of nanoparticles due to their excellent properties. CNTs have better efficiency for the reduction of organic chemicals than activated carbon. The external surfaces of CNTs act as adsorption spots [48-52]. Some research indicates that CNTs aligned in one direction will serve as an active center for active or gating for water transport [53]. A molecular dynamics study states the effectiveness of CNTs for desalination of water in RO systems.

In the aqueous environment, the surface area decreases because of the high hydrophobicity and high interstitial spaces. They are the better absorbents for heavy metals (Fig 3). As they have a small interparticle distance, the adsorption kinetics are high-speed. CNTs, along with nitric acid and $\mathrm{KMNO}_{4}$, help remove $\mathrm{Cd}^{+2}$ ions from the aqueous solution. They have $0.25 \times 10^{12}$ pores per $\mathrm{cm}^{2}$ [54]. The more practical approach of aligning Dehler $e t$ al. filters with CNTs along with hydrophobic membranes.

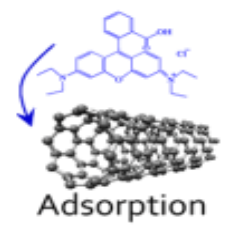

(a)

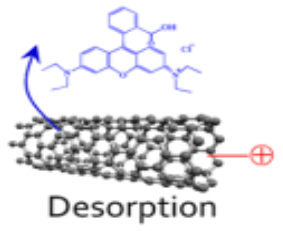

(b)

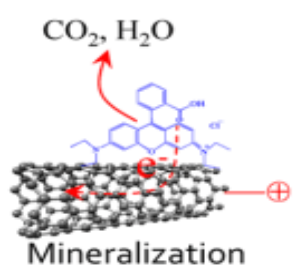

(c)

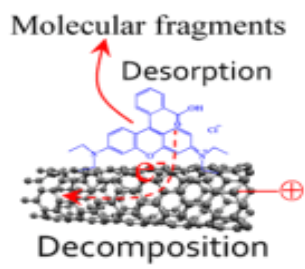

(d)

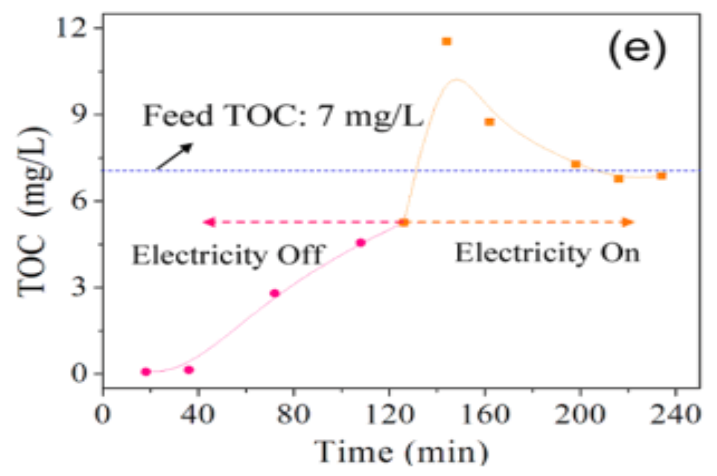

Figure 3 CNTs performances for efficient water treatments [55]. Reprinted (adapted) with permission from ACS Environmental science \& technology; 10.1021/es500506w. Copyright (2014) American Chemical Society.

CNTs have antibacterial mechanism properties and electrochemical behavior where microorganisms are trapped through oxidation, bypassing small intermittent voltage[56-59]. Electrophoresis of the viruses towards the CNTs can give the electric potential, negatively impacting the organic matter in the CNT filter as a virus trap. CNTs and fullerene can generate ROS in water as they are photosensitive, and activation can be activated [60]. There is enough research and development done where single-wall CNTs (SWCNTs) and multiwall (MWCNTs) are directly involved in water desalination. Md. Eaqub Ali and others [61-65], in 
their research, showed that the smooth and the internal core of CNTs could be used for filtration.

The general type of CNT is pristine CNT. It has an aggregating property that significantly lowers water output and pollution rejection capabilities from membranes containing metal catalysts, physical heterogeneous, and impurities [66].

The application of purification of water through the CNTs can also be linked with the surface tension. CNTs coated with polytetrafluoroethylene [PTFE] have no wetting property, which gives better purification property. By applying the voltage, the hydrophobicity of the nanotubes can easily be manipulated to a new value. The hydrophobic nature changes to hydrophilic incrementally with $+2.6 \mathrm{v}$ potential used [67-70].

\subsection{Graphene}

Another type of Nano carbon-based material is Graphene oxide [GO]. Henriques found a new way by making GO foam, which removes $96 \%$ of mercury in 24 hours, which was tested on the river and seawater samples. Synthesized with the precipitation method, the GO membrane can remove cadmium and ionic dyes.

From the commercial point of view, graphene is economical than CNTs with limited commercial applications because of their high price [71]. Graphene has a thick layer lattice, which is an allotrope of carbon with $\mathrm{SP}^{2}$ bonded carbon atom's hexagonal structure. It is impermeable to small molecules with high mechanical properties. In most practical and industrial applications, graphene has increased importance as a desalination membrane [72]. Mishra and Ramaprabhu carried out the experimental work on seawater's desalination by a supercapacitor. f-HEG loading resulted in 55\% arsenic at the electrode and sodium removal from sodium arsenate up to $66 \%$. They found high adsorption capacities, even at 142, 139, 122 $\mathrm{mg} / \mathrm{g}$. This provides a commercial platform for the development of compactable supercapacitors. The graphene nanocomposite also can be used as a functional electrode for CDI [73]. The graphene electrode consists of reduced rGO-RFshowed more significant potential in adsorption.

The new one-pot method revealed excellent results on adsorption of salt removal with an efficiency of $\sim 93 \%$ and different electropositive capacity of $5 \mathrm{mg} \mathrm{g}^{-1}$, specific capabilities up to $292 \mathrm{~F} \mathrm{~g}^{-1}$, and adequate recycling capacity [74].

Desired size Nanopores can be fabricated on graphene by ion bombardment, electron beam irritation, oxidation, chemical etching, di-block copolymer templating, and doping [75]. Salt rejection up to $5.5 \mathrm{~A}$ is possible through the molecular dynamics study through the graphene membranes shown in (Fig 4). Theory shows the use of regular-sized pores for RO.

(a)
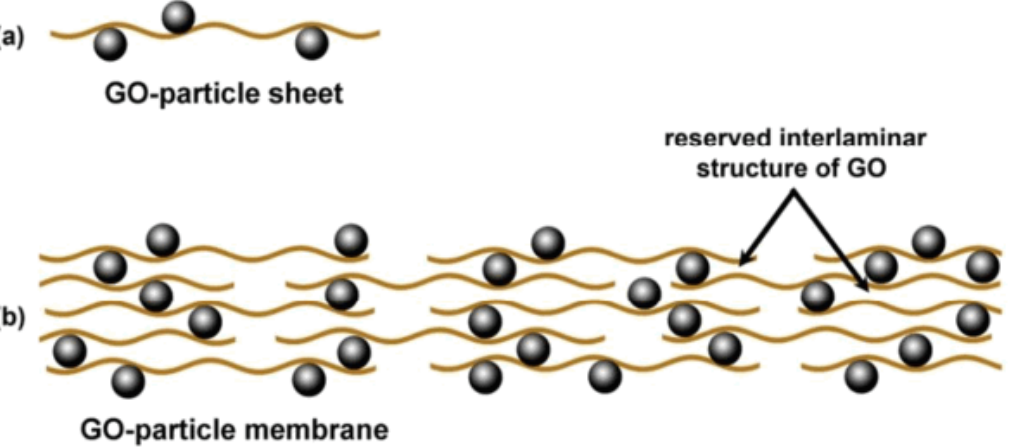

Figure 4. Illustration of a) sheets and b) the membrane of GO [76]. Reprinted (adapted) with permission from ACS Applied Materials \& Interfaces; 10.1021/am5040945. Copyright (2014) American Chemical Society. 
Graphene gave the flexibility to embed in the matrix with all the free-standing membranes. It acts like an incorporated polymer matrix. Incorporating is a highly efficient method than surface coating. The above work showed that graphene Nanopores, which are ve, have an excellent capacity to reject salt ions. The integration of graphene oxide sheets with the polymers has shown an increment in the sheets [76].

\subsection{Metal-based nano absorbents}

Metal-based Nano absorbents, in general, are primarily metal-oxide NPs. These have a higher tendency to absorb heavy metals over activated carbon [77]. Previous researchers showed a nanoscale effect because of its increment in the surface as we go down to much smaller and lower sizes into a nanometre. Yean showed this size effect in 2005, where he experimented by decreasing the size. Shorter interparticle distance and the greater surface area are responsible for the adsorption capacity [78].

In his next research, the same researcher showed the comparison between the Nanotubes and the Nanorods and proved that Nanorods are more efficient in the adsorption of other metal ions. Nano hematite can carry out the reduction of heavy metal lead ions by endothermic and exothermic $\mathrm{Zn}$ reactions. These allow heavy metal adsorption effectively. Nano maghemite and nanomagnets are considered superparamagnetic in iron oxide-based Nanoparticles. Magnetism is taken as an advantage in this case. Metal oxide nanocrystals porous pellets can also be used in industries; fine powders and pellets are used, which is advantageous [79]. Conjugation of $\mathrm{MgO}$ and $\mathrm{TiO}_{2}$ also increases the effectiveness of absorption. Long reactive iron nanoparticles in a size range of 10-100nm explain the effectiveness of chlorine-containing compounds neurotoxicants. They are pre absorbed to zerovalent $\mathrm{Fe}$, with the formation of ethane by reductionC $\mathrm{C}_{2} \mathrm{Cl}_{4}+4 \mathrm{FeO}+4 \mathrm{H}^{+} \rightarrow \mathrm{C}_{2} \mathrm{H}_{4}+4 \mathrm{Fe}_{2}{ }^{+}+$ $4 \mathrm{Cl}^{-}$.

\subsection{Polymeric biomimetic hybrid protein membranes.}

Biomimetic polymeric proteins are suitable for extensive selective transport of solute and the solution (water) to pass through the biological membranes. Cross-linking of the matrix can be achieved through UV light irradiation, which helps to cross-link the matrix. It can be done by free radical initiators such as azobisisobutyronitrile [79]. Kaufman et al.demonstrated the lipid bye layer's usefulness. A recent approach has shown that AQOs are first incorporated into proteoliposomes. The resulting structure will have a cross-linked polyimide coating film. AQP containing proteoliposomes is introduced into a thin film of polyamide during the interfacial polymerization process and acts as a gateway for the selective RO membrane. As a naturally occurring polymer, cellulose is one of them having novel biopolymer-based Nanocomposites with unique properties. This had an interwoven structure. It can form a porous membrane with high mechanical strength $[80,81]$.

\subsection{Polymeric nano absorbents.}

Recently research gained interest in polymeric nano adsorbents as well. These shells will have a good adsorption capacity of up to a $\mathrm{pH}$ of 5.5 by removing the heavy metals. This has recyclability four times. Another study showed that bimetal doped Nano and micro functional polymeric adsorbents showed more significant fluoride and arsenic adsorption potential. A suspension is prepared with it. To obtain bimetal-doped, Nano-adsorbent $\mathrm{Al}$ and 
Fe ions were substituted. It demonstrated better adsorption towards fluorine concerning arsenic [82]. It has its specialty for water purification of iron oxide aggregation in a solitary manner and a stabilizing scaffold for reactive nanoparticles to remove arsenic. Tomographic images of AFM for raw and propionate lignin Nanocomposite depict that after propionate smoothing. Poly-amidoamine has excellent properties of uranium adsorption [83-86].

\subsection{Nanofiber membranes.}

Nanofiber membrane is synthesized with the electrospinning method using hundreds of polymers. Its characterization, Preparation, and selectivity depend on the situation presented in the literature[87-90]. This has hydrophobic nature, which reduces the fouling.

This can remove the bacteria and viruses based on their size, and it is capable of ultrafiltration and reverse osmosis techniques. Sato et al. and others [91-95], in their research, removed E.coli maintaining the continuous flow. Nanofibers help eliminate the microorganisms by having a negative surface charge they dispersed over a micro-glass for nanoparticle-based filtration; this is another approach for nanofiber processing.

Alumina was used for the making of porous membranes Fig. 5 (a). The study on the pour sizes gives information about the porous ceramic membranes, which are around $60 \mathrm{~nm}$ [96] Fig.5 (b).

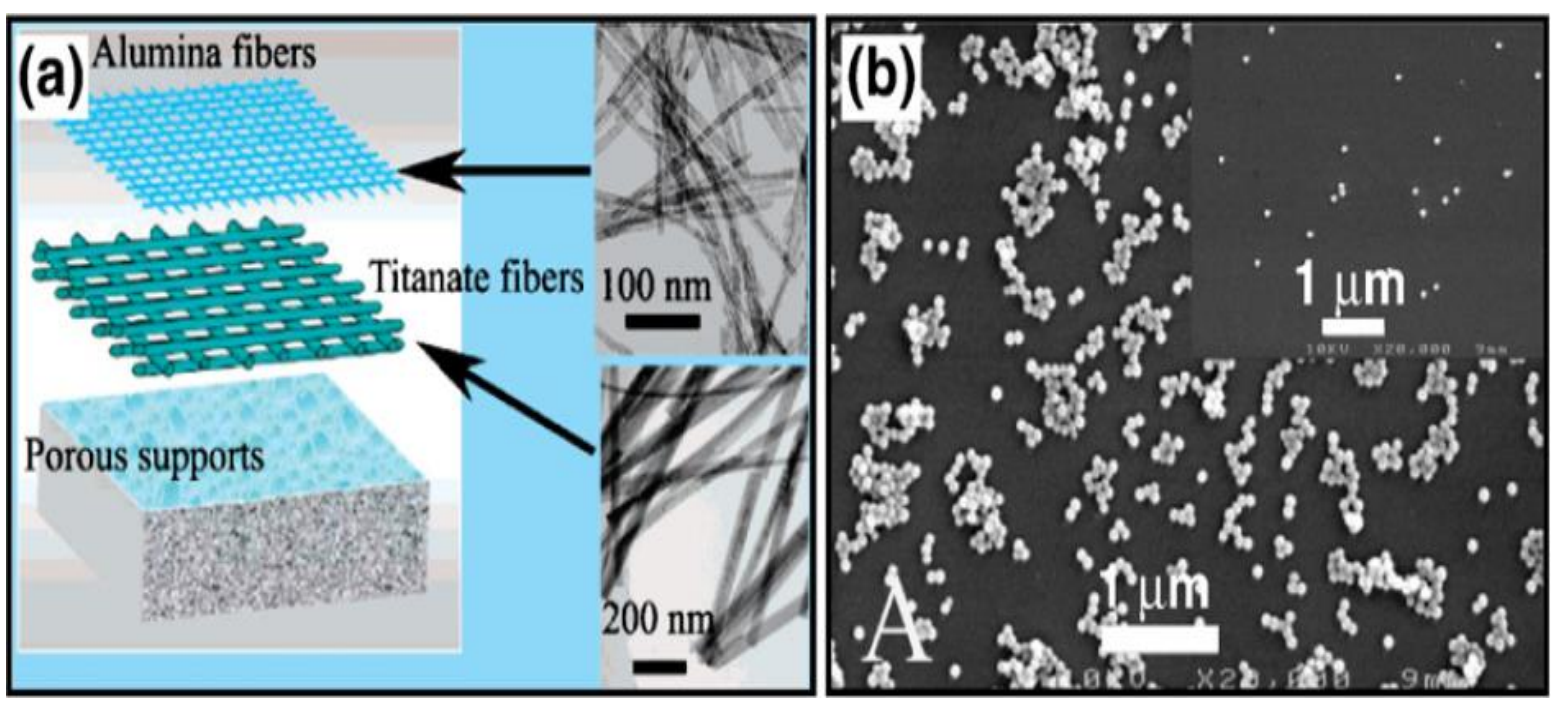

Figure 5. (a) Schematic structure and (b) SEM of nanomesh porous structures [96]. Reprinted (adapted) with permission from ACS Journal of Physical Chemistry B; 10.1021/jp709837r. Copyright (2008) American Chemical Society.

\section{9. $\mathrm{TiO}_{2}$ Nanoparticles.}

$\mathrm{TiO}_{2}$ nanoparticles are also in use to treat wastewaters with inactive microbes. Incorporating Nano $\mathrm{TiO}_{2}$ into TFC active membrane layer with five wt.\% slightly increases permeability [97]. This polymeric membrane will have long-term efficiency. Embedding the functional Nanomaterials into the membranes will significantly improve the properties like mechanical permeability, fouling resistance, thermal stability, and creating new functional groups for removing contaminants and self-cleaning membranes [98-100]. 


\subsection{Ag nanoparticles.}

Silver has been a familiar and good antibacterial for ages. This can be used as a remedy for the decontamination of water. The features contain antimicrobial activity, easy to fabricate, and are safe. Nanosilver has to be taken in proper doses. If not, it becomes toxic, and its toxicity depends on the shape, size, and coating. In another study shows that silver ions favor E.coli growth. The incorporation of Nanosilver into ceramic microfibers acts as a barrier for pathogens [101-103].

\subsection{ZnO nanoparticles.}

$\mathrm{ZnO}$ has an excellent property of absorption of UV light. ZnO NPs will work effectively as an antibacterial agents. The antibacterial action is still unknown; it may depend on the particle size effects [104]. The reason might suggest the photocatalytic effect of $\mathrm{H}_{2} \mathrm{O}_{2}$ on the microbial activity of $\mathrm{ZnO}$. Even though it has an easy nature for dissolving, but it has a limited application in practice.

\subsection{D nanoparticles.}

The unique absorption property of 2D Mxene made it a more exciting point of exploration in wastewater treatment Mxene shows more effective for reducing heavy ions. The application of Mxene started with its unique property of having various functional groups and more surface area compared to other metals used in purification methods. Mxene nanosheets will remove Chromium (iv) ions by reducing Chromium (iv) ions into Chromium (iii), the positively charged Mxene surface with the high number of the hydroxyl group at low $\mathrm{pH}$ will attract the negatively charged chromium ions through electrostatic attraction and also showed more excellent application in the removal of oxidants in the wastewater [105].

Removing non-biodegradable heavy metals from that aquatic life was a challenge for a few years, but the Mxene nanosheets made it easier by trapping the heavy metals in the space between its layers; the larger surface area will also play a significant role in absorption between the layers this happens mainly due to the presence of titanium which has the more excellent capability of attracting the heavy metals by forming the covalent bands with respective elements.

\section{Conclusions}

Nanotechnology enables us to make water purification with a low-cost approach to the popular RO membranes, especially for longer cycles of reuse and desalination. TFN membranes, Zeolite-coated ceramics, Carbon-based materials, Metal-Based Nano absorbents, Hybrid protein-polymer biomimetic membranes, Polymeric Nano absorbents, Nanofiber membranes, $\mathrm{TiO}_{2}$ Nanoparticles, Ag Nanoparticles, $\mathrm{ZnO}$ nanoparticles, Magnet based have made their contributions to the purification. These different particles or elements have been developed through the incorporation of nanotechnology.

The zeolite-coated ceramic membranes give a promising selectivity, with high separation capabilities that can replace polymer membranes earlier. TFNs with nanosilver coating will have good hydrophobicity, have good resistance to fouling. These are titania nanoparticles with membranes of self-cleaning properties. 
CNTs have the remarkable property of self-alignment with the potential application, having a more extraordinary ability to adapt the functionality that can be manipulated according to the need. The challenges faced are temporary where we lack economic support and a significant amount of research in the multidisciplinary streams of nanotechnology. Hence, introducing nanotechnology will help robust solutions for water purification for both incremental and revolutionary purposes.

\section{Funding}

This research received no external funding.

\section{Acknowledgments}

P. Banerjee is a P.I. with grant no. F.30-457/2018 (BSR) from UGC, New Delhi.

\section{Conflicts of Interest}

The authors declare no conflict of interest.

\section{References}

1. Gruère, G.; Narrod, C.; Abbott, L. Agricultural, food, and water nanotechnologies for the poor. International Food Policy Research Institute, Washington, DC 2011, https://doi.org/10.1093/benz/9780199773787.article.b00079870.

2. Fendler, J.H. Colloid chemical approach to nanotechnology. Korean Journal of Chemical Engineering 2001, 18, 1-13, https://doi.org/10.1007/BF02707191.

3. Huerta-Fontela, M.; Galceran, M.T.; Ventura, F. Stimulatory Drugs of Abuse in Surface Waters and Their Removal in a Conventional Drinking Water Treatment Plant. Environmental Science \& Technology 2008, 42, 6809-6816, https://doi.org/10.1021/es800768h.

4. WHO, Progress on Sanitation and Drinking-Water, 2013; pp. 40, (https://www.who.int/water_sanitation_health/publications/2013/jmp_report/en/).

5. Qu, X.; Brame, J.; Li, Q.; Alvarez, P.J.J. Nanotechnology for a Safe and Sustainable Water Supply: Enabling Integrated Water Treatment and Reuse. Accounts of Chemical Research 2013, 46, 834-843, https://doi.org/10.1021/ar300029v.

6. Musico, Y.L.F.; Santos, C.M.; Dalida, M.L.P.; Rodrigues, D.F. Surface Modification of Membrane Filters Using Graphene and Graphene Oxide-Based Nanomaterials for Bacterial Inactivation and Removal. ACS Sustainable Chemistry \& Engineering 2014, 2, 1559-1565, https://doi.org/10.1021/sc500044p.

7. Gupta, V.K.; Ali, I.; Saleh, T.A.; Nayak, A.; Agarwal, S. Chemical treatment technologies for wastewater recycling - an overview. RSC Advances 2012, 2, 6380-6388, https://doi.org/10.1039/C2RA20340E.

8. Hu, H.; Jin, Q.; Kavan, P. A Study of Heavy Metal Pollution in China: Current Status, Pollution-Control Policies and Countermeasures. Sustainability 2014, 6, 5820-5838. https://doi.org/10.3390/su6095820.

9. DeFriend, K.A.; Wiesner, M.R.; Barron, A.R. Alumina and aluminate ultrafiltration membranes derived from alumina nanoparticles. Journal of Membrane Science 2003, 224, 11-28, https://doi.org/10.1016/S03767388(03)00344-2.

10. Stanton, B.W.; Harris, J.J.; Miller, M.D.; Bruening, M.L. Ultrathin, Multilayered Polyelectrolyte Films as Nanofiltration Membranes. Langmuir 2003, 19, 7038-7042, https://doi.org/10.1021/la034603a.

11. Bhattacharyya, D.; Hestekin, J.A.; Brushaber, P.; Cullen, L.; Bachas, L.G.; Sikdar, S.K. Novel poly-glutamic acid functionalized microfiltration membranes for sorption of heavy metals at high capacity. Journal of Membrane Science 1998, 141, 121-135, https://doi.org/10.1016/S0376-7388(97)00301-3.

12. Dotzauer, D.M.; Dai, J.; Sun, L.; Bruening, M.L. Catalytic Membranes Prepared Using Layer-by-Layer Adsorption of Polyelectrolyte/Metal Nanoparticle Films in Porous Supports. Nano Letters 2006, 6, 22682272, https://doi.org/10.1021/nl061700q.

13. Arkas, M.; Eleades, L.; Paleos, C.M.; Tsiourvas, D. Alkylated hyperbranched polymers as molecular nanosponges for the purification of water from polycyclic aromatic hydrocarbons. Journal of Applied Polymer Science 2005, 97, 2299-2305, https://doi.org/10.1002/app.22026.

14. Zhang, H.; Quan, X.; Chen, S.; Zhao, H.; Zhao, Y. Fabrication of photocatalytic membrane and evaluation its efficiency in removal of organic pollutants from water. Separation and Purification Technology 2006, 50, 147-155, https://doi.org/10.1016/j.seppur.2005.11.018. 
15. Athanasekou, C.P.; Romanos, G.E.; Katsaros, F.K.; Kordatos, K.; Likodimos, V.; Falaras, P. Very efficient composite titania membranes in hybrid ultrafiltration/photocatalysis water treatment processes. Journal of Membrane Science 2012, 392-393, 192-203, https://doi.org/10.1016/j.memsci.2011.12.028.

16. Allabashi, R.; Arkas, M.; Hörmann, G.; Tsiourvas, D. Removal of some organic pollutants in water employing ceramic membranes impregnated with cross-linked silylated dendritic and cyclodextrin polymers. Water Research 2007, 41, 476-486, https://doi.org/10.1016/j.watres.2006.10.011.

17. Song, W.; Justice, R.E.; Jones, C.A.; Grassian, V.H.; Larsen, S.C. Synthesis, Characterization, and Adsorption Properties of Nanocrystalline ZSM-5. Langmuir 2004, 20, 8301-8306, https://doi.org/10.1021/la049516c.

18. Orha, C.; Pop, A.; Lazau, C.; Grozescu, I.; Tiponut, V.; Manea, F. Structural characterization and the sorption properties of the natural and synthetic zeolite. J. Optoelectron, Adv. Mater. 2011, 13, 544-549, https://doi.org/10.1109/smicnd.2011.6095797.

19. Peng, X.; Li, Y.; Luan, Z.; Di, Z.; Wang, H.; Tian, B.; Jia, Z. Adsorption of 1,2-dichlorobenzene from water to carbon nanotubes. Chemical Physics Letters 2003, 376, 154-158, https://doi.org/10.1016/S00092614(03)00960-6.

20. Di, Z.-C.; Ding, J.; Peng, X.-J.; Li, Y.-H.; Luan, Z.-K.; Liang, J. Chromium adsorption by aligned carbon nanotubes supported ceria nanoparticles. Chemosphere 2006, 62, 861-865, https://doi.org/10.1016/j.chemosphere.2004.06.044.

21. Salipira, K.L.; Mamba, B.B.; Krause, R.W.; Malefetse, T.J.; Durbach, S.H. Carbon nanotubes and cyclodextrin polymers for removing organic pollutants from water. Environmental Chemistry Letters 2007, 5, 13-17, https://doi.org/10.1007/s10311-006-0057-y.

22. Khaydarov, R.A.; Khaydarov, R.R.; Gapurova, O. Water purification from metal ions using carbon nanoparticle-conjugated polymer nanocomposites. Water Research 2010, 44, 1927-1933, https://doi.org/10.1016/j.watres.2009.11.041.

23. Poinern, G.E.J.; Parsonage, D.; Issa, T.B.; Ghosh, M.; Paling, E.; Singh, P. Preparation, characterization and As (V) adsorption behaviour of CNT-ferrihydrite composites. Int. J. Eng. Sci. Technol 2010, 2, 13-24, https://doi.org/10.4314/ijest.v2i8.63776.

24. Tofighy, M.A.; Mohammadi, T. Adsorption of divalent heavy metal ions from water using carbon nanotube sheets. Journal of Hazardous Materials 2011, 185, 140-147, https://doi.org/10.1016/j.jhazmat.2010.09.008.

25. Jin, J.; Li, R.; Wang, H.; Chen, H.; Liang, K.; Ma, J. Magnetic Fe nanoparticle functionalized water-soluble multi-walled carbon nanotubules towards the preparation of sorbent for aromatic compounds removal. Chemical Communications 2007, 386-388, https://doi.org/10.1039/B610842C.

26. Lu, C.; Chung, Y.-L.; Chang, K.-F. Adsorption of trihalomethanes from water with carbon nanotubes. Water Research 2005, 39, 1183-1189, https://doi.org/10.1016/j.watres.2004.12.033.

27. Guo, L.; Li, J.; Zhang, L.; Li, J.; Li, Y.; Yu, C.; Shi, J.; Ruan, M.; Feng, J. A facile route to synthesize magnetic particles within hollow mesoporous spheres and their performance as separable $\mathrm{Hg} 2+$ adsorbents. Journal of Materials Chemistry 2008, 18, 2733-2738, https://doi.org/10.1039/B802857E.

28. Huang, C.; Hu, B. Silica-coated magnetic nanoparticles modified with $\gamma$-mercaptopropyltrimethoxysilane for fast and selective solid phase extraction of trace amounts of $\mathrm{Cd}, \mathrm{Cu}, \mathrm{Hg}$, and $\mathrm{Pb}$ in environmental and biological samples prior to their determination by inductively coupled plasma mass spectrometry. Spectrochimica Acta Part B: Atomic Spectroscopy 2008, 63, 437-444, https://doi.org/10.1016/j.sab.2007.12.010.

29. Shin, S.; Jang, J. Thiol containing polymer encapsulated magnetic nanoparticles as reusable and efficiently separable adsorbent for heavy metal ions. Chemical Communications 2007, 4230-4232, https://doi.org/10.1039/B707706H.

30. He, F.; Zhao, D. Preparation and Characterization of a New Class of Starch-Stabilized Bimetallic Nanoparticles for Degradation of Chlorinated Hydrocarbons in Water. Environmental Science \& Technology 2005, 39, 3314-3320, https://doi.org/10.1021/es048743y.

31. Álvarez-Ayuso, E.; García-Sánchez, A.; Querol, X. Purification of metal electroplating waste waters using zeolites. Water Research 2003, 37, 4855-4862, https://doi.org/10.1016/j.watres.2003.08.009.

32. Zhang, Y.; Wang, F.; Wang, Y. Recent developments of electrospun nanofibrous materials as novel adsorbents for water treatment. Materials Today Communications 2021, 27, https://doi.org/10.1016/j.mtcomm.2021.102272.

33. Naim, R.; Hazmo, N.H.W.; Woei Jye, L.; Ismail, A.F. Effect of Composite Multi-Walled Carbon Nanotube and Zeolitic Imidazolate Framework-8 on the Performance and Fouling of PVDF Membranes. Journal of Membrane Science and Research 2020, 6, 424-432.

34. Gusain, R.; Kumar, N.; Ray, S.S. Recent advances in carbon nanomaterial-based adsorbents for water purification. Coordination Chemistry Reviews 2020, 405, https://doi.org/10.1016/j.ccr.2019.213111.

35. Li, L.; Dong, J.; Nenoff, T.M.; Lee, R. Desalination by reverse osmosis using MFI zeolite membranes. Journal of Membrane Science 2004, 243, 401-404, https://doi.org/10.1016/j.memsci.2004.06.045.

36. Mamah, S.C.; Goh, P.S.; Ismail, A.F.; Suzaimi, N.D.; Ahmad, N.A.; Lee, W.J. Flux enhancement in reverse osmosis membranes induced by synergistic effect of incorporated palygorskite/chitin hybrid nanomaterial. Journal of Environmental Chemical Engineering 2021, 9, https://doi.org/10.1016/j.jece.2021.105432. 
37. da Silva Alves, D.C.; Healy, B.; Pinto, L.A.d.A.; Cadaval, T.R.S.A.; Breslin, C.B. Recent Developments in Chitosan-Based Adsorbents for the Removal of Pollutants from Aqueous Environments. Molecules 2021, 26, https://doi.org/10.3390/molecules26030594.

38. Khodakarami, M.; Bagheri, M. Recent advances in synthesis and application of polymer nanocomposites for water and wastewater treatment. Journal of Cleaner Production 2021, 296, https://doi.org/10.1016/j.jclepro.2021.126404.

39. Elgarahy, A.M.; Elwakeel, K.Z.; Akhdhar, A.; Hamza, M.F. Recent advances in greenly synthesized nanoengineered materials for water/wastewater remediation: an overview. Nanotechnology for Environmental Engineering 2021, 6, 1-24, https://doi.org/10.1007/s41204-021-00104-5.

40. Singh, R.; Singh, M.; Kumari, N.; Janak; Maharana, S.; Maharana, P. A Comprehensive Review of Polymeric Wastewater Purification Membranes. Journal of Composites Science 2021, 5, https://doi.org/10.3390/jcs5060162.

41. Zhang, W.; Shi, S.; Zhu, W.; Huang, L.; Yang, C.; Li, S.; Liu, X.; Wang, R.; Hu, N.; Suo, Y.; Li, Z.; Wang, J. Agar Aerogel Containing Small-Sized Zeolitic Imidazolate Framework Loaded Carbon Nitride: A SolarTriggered Regenerable Decontaminant for Convenient and Enhanced Water Purification. ACS Sustainable Chemistry \& Engineering 2017, 5, 9347-9354, https://doi.org/10.1021/acssuschemeng.7b02376.

42. Luo, J.; Yu, D.; Hristovski, K.D.; Fu, K.; Shen, Y.; Westerhoff, P.; Crittenden, J.C. Critical Review of Advances in Engineering Nanomaterial Adsorbents for Metal Removal and Recovery from Water: Mechanism Identification and Engineering Design. Environmental Science \& Technology 2021, 55, 42874304, https://doi.org/10.1021/acs.est.0c07936.

43. Amen, R.; Bibi, I.; Shahid, M.; Niazi, N.K.; Zulfqar, A.; Nawaz, M.F.; Shakoor, M.B.; Mukhtar, A.; Rehman, T. Developments in Nanoadsorbents for the Treatment of Arsenic-Contaminated Water. In: Arsenic Toxicity: Challenges and Solutions. Kumar, N. Ed.; Springer Singapore: Singapore, 2021; pp. 325-361, https://doi.org/10.1007/978-981-33-6068-6_13.

44. Dutta, S.; Gupta, B.; Srivastava, S.K.; Gupta, A.K. Recent advances on the removal of dyes from wastewater using various adsorbents: a critical review. Materials Advances 2021, 2, 4497-4531, https://doi.org/10.1039/D1MA00354B.

45. Mahmoud, K.A.; Mansoor, B.; Mansour, A.; Khraisheh, M. Functional graphene nanosheets: The next generation membranes for water desalination. Desalination 2015, 356, 208-225, https://doi.org/10.1016/j.desal.2014.10.022.

46. Taurozzi, J.S.; Arul, H.; Bosak, V.Z.; Burban, A.F.; Voice, T.C.; Bruening, M.L.; Tarabara, V.V. Effect of filler incorporation route on the properties of polysulfone-silver nanocomposite membranes of different porosities. Journal of Membrane Science 2008, 325, 58-68, https://doi.org/10.1016/j.memsci.2008.07.010.

47. Pan, B.; Xing, B. Adsorption Mechanisms of Organic Chemicals on Carbon Nanotubes. Environmental Science \& Technology 2008, 42, 9005-9013, https://doi.org/10.1021/es801777n.

48. van Hijkoop, V.J.; Dammers, A.J.; Malek, K.; Coppens, M.-O. Water diffusion through a membrane protein channel: A first passage time approach. The Journal of Chemical Physics 2007, 127, https://doi.org/10.1063/1.2761897.

49. Bhowmick, K.; Roy, S.; Mukherjee, M.; Sahoo, G.C.; Majumdar, S.; Mondal, P. Removal of cadmium by insitu $\mathrm{Cu}$ nanoparticle enhanced ceramic-supported-polymeric composite NF membrane. Materials Today: Proceedings 2021, https://doi.org/10.1016/j.matpr.2021.04.398.

50. Younas, F.; Mustafa, A.; Farooqi, Z.U.; Wang, X.; Younas, S.; Mohy-Ud-Din, W.; Ashir Hameed, M.; Mohsin Abrar, M.; Maitlo, A.A.; Noreen, S.; Hussain, M.M. Current and Emerging Adsorbent Technologies for Wastewater Treatment: Trends, Limitations, and Environmental Implications. Water 2021, 13, https://doi.org/10.3390/w13020215.

51. Boix, G.; Han, X.; Imaz, I.; Maspoch, D. Millimeter-Shaped Metal-Organic Framework/Inorganic Nanoparticle Composite as a New Adsorbent for Home Water-Purification Filters. ACS Applied Materials \& Interfaces 2021, 13, 17835-17843, https://doi.org/10.1021/acsami.1c02940.

52. Rashid, R.; Shafiq, I.; Akhter, P.; Iqbal, M.J.; Hussain, M. A state-of-the-art review on wastewater treatment techniques: the effectiveness of adsorption method. Environmental Science and Pollution Research 2021, 28, 9050-9066, https://doi.org/10.1007/s11356-021-12395-x.

53. Corry, B. Designing Carbon Nanotube Membranes for Efficient Water Desalination. The Journal of Physical Chemistry B 2008, 112, 1427-1434, https://doi.org/10.1021/jp709845u.

54. Rao, G.P.; Lu, C.; Su, F. Sorption of divalent metal ions from aqueous solution by carbon nanotubes: A review. Separation and Purification Technology 2007, 58, 224-231, https://doi.org/10.1016/j.seppur.2006.12.006.

55. Wei, G.; Yu, H.; Quan, X.; Chen, S.; Zhao, H.; Fan, X. Constructing All Carbon Nanotube Hollow Fiber Membranes with Improved Performance in Separation and Antifouling for Water Treatment. Environmental Science \& Technology 2014, 48, 8062-8068, https://doi.org/10.1021/es500506w.

56. Rahaman, M.S.; Vecitis, C.D.; Elimelech, M. Electrochemical Carbon-Nanotube Filter Performance toward Virus Removal and Inactivation in the Presence of Natural Organic Matter. Environmental Science \& Technology 2012, 46, 1556-1564, https://doi.org/10.1021/es203607d. 
57. Liu, D.; Gu, W.; Zhou, L.; Wang, L.; Zhang, J.; Liu, Y.; Lei, J. Recent advances in MOF-derived carbonbased nanomaterials for environmental applications in adsorption and catalytic degradation. Chemical Engineering Journal 2022, 427, https://doi.org/10.1016/j.cej.2021.131503.

58. Syahirah Kamarudin, N.; Jusoh, R.; Dina Setiabudi, H.; Fateha Sukor, N.; Haslinda Shariffuddin, J. Potential nanomaterials application in wastewater treatment: Physical, chemical and biological approaches. Materials Today: Proceedings 2021, 42, 107-114, https://doi.org/10.1016/j.matpr.2020.10.221.

59. Ighalo, J.O.; Sagboye, P.A.; Umenweke, G.; Ajala, O.J.; Omoarukhe, F.O.; Adeyanju, C.A.; Ogunniyi, S.; Adeniyi, A.G. $\mathrm{CuO}$ nanoparticles (CuO NPs) for water treatment: A review of recent advances. Environmental Nanotechnology, Monitoring \& $\quad$ Management $2021, \quad 15$, https://doi.org/10.1016/j.enmm.2021.100443.

60. Deng, J.-H.; Zhang, X.-R.; Zeng, G.-M.; Gong, J.-L.; Niu, Q.-Y.; Liang, J. Simultaneous removal of Cd(II) and ionic dyes from aqueous solution using magnetic graphene oxide nanocomposite as an adsorbent. Chemical Engineering Journal 2013, 226, 189-200, https://doi.org/10.1016/j.cej.2013.04.045.

61. Mauter, M.S.; Elimelech, M. Environmental Applications of Carbon-Based Nanomaterials. Environmental Science \& Technology 2008, 42, 5843-5859, https://doi.org/10.1021/es8006904.

62. Bhavya, G.; Belorkar, S.A.; Mythili, R.; Geetha, N.; Shetty, H.S.; Udikeri, S.S.; Jogaiah, S. Remediation of emerging environmental pollutants: A review based on advances in the uses of eco-friendly biofabricated nanomaterials. Chemosphere 2021, 275, https://doi.org/10.1016/j.chemosphere.2021.129975.

63. Yap, P.L.; Nine, M.J.; Hassan, K.; Tung, T.T.; Tran, D.N.H.; Losic, D. Graphene-Based Sorbents for Multipollutants Removal in Water: A Review of Recent Progress. Advanced Functional Materials 2021, 31, https://doi.org/10.1002/adfm.202007356.

64. Choudhary, V.; Vellingiri, K.; Philip, L. Potential nanomaterials-based detection and treatment methods for aqueous chloroform. Environmental Nanotechnology, Monitoring \& Management 2021, 16, https://doi.org/10.1016/j.enmm.2021.100487.

65. Lau, K.K.S.; Bico, J.; Teo, K.B.K.; Chhowalla, M.; Amaratunga, G.A.J.; Milne, W.I.; McKinley, G.H.; Gleason, K.K. Superhydrophobic Carbon Nanotube Forests. Nano Letters 2003, 3, 1701-1705, https://doi.org/10.1021/n1034704t.

66. Palani, G.; Arputhalatha, A.; Kannan, K.; Lakkaboyana, S.K.; Hanafiah, M.M.; Kumar, V.; Marella, R.K. Current Trends in the Application of Nanomaterials for the Removal of Pollutants from Industrial Wastewater Treatment-A Review. Molecules 2021, 26, https://doi.org/10.3390/molecules26092799.

67. Lee, C.; Wei, X.; Kysar Jeffrey, W.; Hone, J. Measurement of the Elastic Properties and Intrinsic Strength of Monolayer Graphene. Science (New York, N.Y.) 2008, 321, 385-388, https://doi.org/10.1126/science.1157996.

68. Thirunavukkarasu, A.; Nithya, R.; Sivashankar, R. A review on the role of nanomaterials in the removal of organic pollutants from wastewater. Reviews in Environmental Science and Bio/Technology 2020, 19, 751778, https://doi.org/10.1007/s11157-020-09548-8.

69. Nasrollahzadeh, M.; Sajjadi, M.; Iravani, S.; Varma, R.S. Carbon-based sustainable nanomaterials for water treatment: State-of-art and future perspectives. Chemosphere 2021, 263, https://doi.org/10.1016/j.chemosphere.2020.128005.

70. Jinadasa, K.K.; Peña-Vázquez, E.; Bermejo-Barrera, P.; Moreda-Piñeiro, A. New adsorbents based on imprinted polymers and composite nanomaterials for arsenic and mercury screening/speciation: A review. Microchemical Journal 2020, 156, https://doi.org/10.1016/j.microc.2020.104886.

71. Humplik, T.; Lee, J.; O’Hern, S.C.; Fellman, B.A.; Baig, M.A.; Hassan, S.F.; Atieh, M.A.; Rahman, F.; Laoui, T.; Karnik, R.; Wang, E.N. Nanostructured materials for water desalination. Nanotechnology 2011, 22, https://doi.org/10.1088/0957-4484/22/29/292001.

72. Wang, Z.; Dou, B.; Zheng, L.; Zhang, G.; Liu, Z.-T.; Hao, Z. Effective desalination by capacitive deionization with functional graphene nanocomposite as novel electrode material. Desalination 2012, 299, 96-102, https://doi.org/10.1016/j.desal.2012.05.028.

73. Al-Saydeh, S.A.; El-Naas, M.H.; Zaidi, S.J. Copper removal from industrial wastewater: A comprehensive review. Journal of Industrial and Engineering Chemistry 2017, 56, 35-44, https://doi.org/10.1016/j.jiec.2017.07.026.

74. Zhang, J.; Zou, H.; Qing, Q.; Yang, Y.; Li, Q.; Liu, Z.; Guo, X.; Du, Z. Effect of Chemical Oxidation on the Structure of Single-Walled Carbon Nanotubes. The Journal of Physical Chemistry B 2003, 107, 3712-3718, https://doi.org/10.1021/jp027500u.

75. Garaj, S.; Hubbard, W.; Reina, A.; Kong, J.; Branton, D.; Golovchenko, J.A. Graphene as a subnanometre trans-electrode membrane. Nature 2010, 467, 190-193, https://doi.org/10.1038/nature09379.

76. Xu, C.; Xu, Y.; Zhu, J. Photocatalytic Antifouling Graphene Oxide-Mediated Hierarchical Filtration Membranes with Potential Applications on Water Purification. ACS Applied Materials \& Interfaces 2014, 6, 16117-16123, https://doi.org/10.1021/am5040945.

77. Yean, S.; Cong, L.; Yavuz, C.T.; Mayo, J.T.; Yu, W.W.; Kan, A.T.; Colvin, V.L.; Tomson, M.B. Effect of magnetite particle size on adsorption and desorption of arsenite and arsenate. J. Mater. Res. 2005, 20, 32553264, https://doi.org/10.1557/jmr.2005.0403e. 
78. Shipley, H.J.; Engates, K.E.; Grover, V.A. Removal of $\mathrm{Pb}(\mathrm{II}), \mathrm{Cd}(\mathrm{II}), \mathrm{Cu}(\mathrm{II})$, and $\mathrm{Zn}$ (II) by hematite nanoparticles: effect of sorbent concentration, $\mathrm{pH}$, temperature, and exhaustion. Environmental Science and Pollution Research 2013, 20, 1727-1736, https://doi.org/10.1007/s11356-012-0984-z.

79. Ho, D.; Chu, B.; Schmidt, J.J.; Brooks, E.K.; Montemagno, C.D. Hybrid proteinpolymer biomimetic membranes. IEEE T.Nanotechnol. 2004, 3, 256-263, https://doi.org/10.1109/TNANO.2004.828530.

80. Taniguchi, T.; Okamura, K. New films produced from microfibrillated natural fibres. Polymer International 1998, 47, 291-294, https://doi.org/10.1002/(SICI)1097-0126(199811)47:3<291::AID-PI11>3.0.CO;2-1.

81. Khajeh, M.; Laurent, S.; Dastafkan, K. Nanoadsorbents: Classification, Preparation, and Applications (with Emphasis on Aqueous Media). Chemical Reviews 2013, 113, 7728-7768, https://doi.org/10.1021/cr400086v.

82. Nata, I.F.; Sureshkumar, M.; Lee, C.-K. One-pot preparation of amine-rich magnetite/bacterial cellulose nanocomposite and its application for arsenate removal. RSC Advances 2011, 1, 625-631, https://doi.org/10.1039/C1RA00153A.

83. Ahmed, F.E.; Lalia, B.S.; Hashaikeh, R. A review on electrospinning for membrane fabrication: Challenges and applications. Desalination 2015, 356, 15-30, https://doi.org/10.1016/j.desal.2014.09.033.

84. Khalid, Z.B.; Mohd, N.; Abdullah, N.; Zularisam, A.W.; Lakhveer, S.; Santhana, K. Application of 2D Graphene-Based Nanomaterials for Pollutant Removal from Advanced Water and Wastewater Treatment Processes. In: Adapting 2D Nanomaterials for Advanced Applications.. American Chemical Society. 2020; pp. 191-217, https://doi.org/10.1021/bk-2020-1353.ch009.

85. Zeng, M.; Chen, M.; Huang, D.; Lei, S.; Zhang, X.; Wang, L.; Cheng, Z. Engineered two-dimensional nanomaterials: an emerging paradigm for water purification and monitoring. Materials Horizons 2021, 8, 758-802, https://doi.org/10.1039/D0MH01358G.

86. Liu, H.; Qiu, H. Recent advances of 3D graphene-based adsorbents for sample preparation of water pollutants: A review. Chemical Engineering Journal 2020, 393, https://doi.org/10.1016/j.cej.2020.124691.

87. Nasreen, S.A.; Sundarrajan, S.; Nizar, S.A.; Balamurugan, R.; Ramakrishna, S. Advancement in Electrospun Nanofibrous Membranes Modification and Their Application in Water Treatment. Membranes 2013, 3, 266284, https://doi.org/10.3390/membranes3040266.

88. Gupta, K.; Joshi, P.; Gusain, R.; Khatri, O.P. Recent advances in adsorptive removal of heavy metal and metalloid ions by metal oxide-based nanomaterials. Coordination Chemistry Reviews 2021, 445, https://doi.org/10.1016/j.ccr.2021.214100.

89. Hu, X.; You, S.; Li, F.; Liu, Y. Recent advances in antimony removal using carbon-based nanomaterials: A review. Frontiers of Environmental Science \& Engineering 2021, 16, https://doi.org/10.1007/s11783-0211482-7.

90. Dlamini, D.S.; Tesha, J.M.; Vilakati, G.D.; Mamba, B.B.; Mishra, A.K.; Thwala, J.M.; Li, J. A critical review of selected membrane- and powder-based adsorbents for water treatment: Sustainability and effectiveness. Journal of Cleaner Production 2020, 277, https://doi.org/10.1016/j.jclepro.2020.123497.

91. Chu, Y.H.; Cruz, M.P.; Yang, C.H.; Martin, L.W.; Yang, P.L.; Zhang, J.X.; Lee, K.; Yu, P.; Chen, L.Q.; Ramesh, R. Domain Control in Multiferroic BiFeO3 through Substrate Vicinality. Advanced Materials 2007, 19, 2662-2666, https://doi.org/10.1002/adma.200602972.

92. Tom, A.P. Nanotechnology for sustainable water treatment - A review. Materials Today: Proceedings 2021, https://doi.org/10.1016/j.matpr.2021.05.629.

93. Biftu, W.K.; Ravindhranath, K.; Ramamoorty, M. New research trends in the processing and applications of iron-based nanoparticles as adsorbents in water remediation methods. Nanotechnology for Environmental Engineering 2020, 5, https://doi.org/10.1007/s41204-020-00076-y.

94. Manikandan, S.; Karmegam, N.; Subbaiya, R.; Karthiga Devi, G.; Arulvel, R.; Ravindran, B.; Kumar Awasthi, M. Emerging nano-structured innovative materials as adsorbents in wastewater treatment. Bioresource Technology 2021, 320, https://doi.org/10.1016/j.biortech.2020.124394.

95. Sridevi, M.; Nirmala, C.; Jawahar, N.; Arthi, G.; Vallinayagam, S.; Sharma, V.K. Role of nanomaterial's as adsorbent for heterogeneous reaction in waste water treatment. Journal of Molecular Structure 2021, 1241, https://doi.org/10.1016/j.molstruc.2021.130596.

96. Ke, X.B.; Zheng, Z.F.; Liu, H.W.; Zhu, H.Y.; Gao, X.P.; Zhang, L.X.; Xu, N.P.; Wang, H.; Zhao, H.J.; Shi, J.; Ratinac, K.R. High-Flux Ceramic Membranes with a Nanomesh of Metal Oxide Nanofibers. The Journal of Physical Chemistry B 2008, 112, 5000-5006, https://doi.org/10.1021/jp709837r.

97. Qu, X.; Alvarez, P.J.J.; Li, Q. Applications of nanotechnology in water and wastewater treatment. Water Research 2013, 47, 3931-3946, http://dx.doi.org/10.1016/j.watres.2012.09.058.

98. Xiu, Z.-M.; Ma, J.; Alvarez, P.J.J. Differential Effect of Common Ligands and Molecular Oxygen on Antimicrobial Activity of Silver Nanoparticles versus Silver Ions. Environmental Science \& Technology 2011, 45, 9003-9008, https://doi.org/10.1021/es201918f.

99. Mehmood, A.; Khan, F.S.A.; Mubarak, N.M.; Tan, Y.H.; Karri, R.R.; Khalid, M.; Walvekar, R.; Abdullah, E.C.; Nizamuddin, S.; Mazari, S.A. Magnetic nanocomposites for sustainable water purification-a comprehensive review. Environmental Science and Pollution Research 2021, 28, 19563-19588, https://doi.org/10.1007/s11356-021-12589-3.

100.Mudhoo, A.; Sillanpää, M. Magnetic nanoadsorbents for micropollutant removal in real water treatment: a review. Environmental Chemistry Letters 2021, https://doi.org/10.1007/s10311-021-01289-6. 
101.Jones, N.; Ray, B.; Ranjit, K.T.; Manna, A.C. Antibacterial activity of ZnO nanoparticle suspensions on a broad spectrum of microorganisms. FEMS Microbiology Letters 2008, 279, 71-76, https://doi.org/10.1111/j.1574-6968.2007.01012.x.

102.Jain, A.; Kumari, S.; Agarwal, S.; Khan, S. Water purification via novel nano-adsorbents and their regeneration strategies. Process Safety and Environmental Protection 2021, 152, 441-454, https://doi.org/10.1016/j.psep.2021.06.031.

103. Saleh, T.A. Protocols for synthesis of nanomaterials, polymers, and green materials as adsorbents for water treatment technologies. Environmental Technology \& Innovation 2021, 24, https://doi.org/10.1016/j.eti.2021.101821.

104.Sarkar, A.; Biswas, S.K.; Pramanik, P. Design of a new nanostructure comprising mesoporous $\mathrm{ZrO} 2$ shell and magnetite core $(\mathrm{Fe} 3 \mathrm{O} 4 @ \mathrm{mZrO} 2)$ and study of its phosphate ion separation efficiency. Journal of Materials Chemistry 2010, 20, 4417-4424, https://doi.org/10.1039/B925379C.

105.Ihsanullah, I. MXenes (two-dimensional metal carbides) as emerging nanomaterials for water purification: Progress, challenges and prospects. Chemical Engineering Journal 2020, 388, https://doi.org/10.1016/j.cej.2020.124340. 